\title{
The flipped classroom model for an undergraduate epidemiology course
}

\author{
Sangho Sohn', Young-Mee Lee ${ }^{2}$, Jaehun Jung ${ }^{1}$, Eun Shil Cha ${ }^{1}$ and Byung Chul Chun ${ }^{1}$ \\ Departments of ${ }^{1}$ Preventive Medicine and ${ }^{2}$ Medical Humanities, Korea University College of Medicine, Seoul, \\ Korea
}

Purpose: The flipped classroom has been suggested as a method for efficient teaching in medical education. However, its feasibility and effectiveness in the educational environment are often overlooked. The authors redesigned an epidemiology course applying the flipped classroom method under a traditional curriculum consisting of heavily scheduled classroom hours and explored its feasibility and effectiveness.

Methods: In the fall semester of 2017, we flipped the 'practice of epidemiology' course for third-year medical students at Korea University College of Medicine. We provided online lectures and assigned readings as pre-class materials, and substituted group discussions and communicative activities for traditional lectures. We conducted pre- and post-course surveys to review students' perceptions. We also analyzed the pre-test results and final exam scores for quantitative comparison.

Results: Ninety-seven students out of 120 completed the course. Most students made use of the online lectures, but not the reading materials. Lack of time was the most frequently cited reason for under-preparedness. We observed improvements in preparedness, participation, and effectiveness at the end of the course, while changes in satisfaction were unclear. Students' perceptions of course relevance and difficulty were predictive of pre-test outcomes, but the effects of preparedness and length of materials were insignificant. The authors found no evidence of differing test scores before and after the course.

Conclusion: This study supports the feasibility of the flipped classroom model even under a traditional, heavily scheduled medical curriculum. To encourage self-directed learning and achieve better learning outcomes, restructuring pre-existing curricular components should also be considered in parallel with new instructional methods.

Key Words: Flipped classroom, Medical education, Teaching, Epidemiology, Preventive medicine

\section{Introduction}

Recent research in medical education underscores the importance of early clinical exposure supported by competency-based learning, facilitating students' development of practical skills and providing more opportunities for medical reasoning [1,2]. One concern over this change is that the timeline for training a student to become a doctor is inflexible, while the medical knowledge to be delivered is continuously growing. Under this circumstance, collaborative or interactive course formats such as problem-based learning might afford opportunities for more efficient time-use [3]. The flipped classroom model is one such rapidly growing alternative [4]: Instructors provide all
Received: February 1, 2019 • Revised: April 1, 2019 • Accepted: May 7, 2019 Corresponding Author: Byung Chul Chun (https://orcid.org/0000-0001-6576-8916) Department of Preventive Medicine, Korea University College of Medicine, 73 Inchon-ro, Seongbuk-gu, Seoul 02841, Korea

Tel: +82.2.2286.1174 Fax: +82.2.927.7220 email: chun@korea.ac.kr
Korean J Med Educ 2019 Jun; 31(2): 103-113.

https://doi.org/10.3946/kjme.2019.122

eISSN: 2005-7288

(C) The Korean Society of Medical Education. All rights reserved. This is an open-access article distributed under the terms of the Creative Commons Attribution Non-Commercial License (http:// creativecommons.org/licenses/by-nc/3.0/), which permits unrestricted non-commercial use, distribution, and reproduction in any medium, provided the original work is properly cited. 
necessary class materials online, including online lecture videos, and allow students to study according to their own schedules. During in-class hours, traditional lectures are replaced by interactive sessions such as group discussions, presentations, and answering questions between students and instructors.

The idea of the flipped classroom is attractive in that it effectively utilizes limited time as well as facilitating interaction to improve learning outcomes [5,6]. For this reason, higher education institutions are beginning to evaluate the feasibility of the flipped learning method in specific circumstances: Medical students in basic medicine courses have shown to adapt well to this format with reasonably satisfactory outcomes [7-9]. Flipped learning has also been evaluated in other health education contexts, such as dentistry and pharmacy courses [10-12].

However, it is unclear whether this approach can also be conducted effectively in contexts of relatively conservative and traditional educational culture, including: (1) heavily scheduled class hours with little time for students' self-directed learning; (2) situations where most teachers still prefer the traditional lecture format; (3) low trust in students' self-directed learning ability; and (4) limited educational resources, such as educationdedicated faculties, compared to western and some advanced Asian medical schools.

Therefore, the purpose of this study was to examine the feasibility of a flipped classroom model in the context of a conventional lecture-based curriculum.

\section{Methods}

Practice of epidemiology is a required course for the third-year medical students of the 6-year curriculum at Korea University College of Medicine. It was scheduled as a 2-hour, once- weekly class that lasted for 5 weeks in the 2017 fall semester.

\section{Study participants}

Prior to the first session, students were informed that the flipped learning method would be implemented in the course. They were also informed that there would be a pre- and post-course survey to evaluate their perceptions of and satisfaction with the course, but participation in the survey was entirely voluntary. For in-class activities such as group discussions, students were randomly allocated to one of 10 groups comprising 12 students each.

Among the 120 students who initially registered for the course, two students withdrew to take a gap year and 21 students refused to turn in the course survey. The final data collected from 97 students (65 males, 32 females; mean age, 22.4 years) were included in the analysis.

\section{Tutors}

Four qualified personnel from the Department of Preventive Medicine assisted with the course as tutors: a professor, M.D., Ph.D., who oversaw the course; a research associate professor with a $\mathrm{Ph} . \mathrm{D}$. in epidemiology; and a preventive medicine specialist and a junior resident, who were both Ph.D. candidates. Each tutor was asked to organize one or two sessions and prepare the corresponding course materials, such as online lectures. They were also assigned as supervisors to two or three groups to facilitate group discussion or help the students stay on track.

\section{Course materials}

\section{1) Pre-class materials}

Pre-class materials, including online lectures and assigned reading materials, were provided to students in advance for independent self-study. Online lectures were produced in the 'Diamond Studio' at Korea 
University College of Medicine, a facility fully equipped with a professional-class audio/video recording system and content-editing software. To ensure student focus for the duration of the online lectures, the tutors were encouraged to adhere to a maximum of 30 minutes of recording time [13]. The lecture clips were uploaded to the YouTube platform and posted online a week prior to each session at the latest through the school's website, called the 'DIAMOND Library (http://medicine.korea. ac.kr/web/diamond-library),' to which all registered students of the university have access. To improve students' understanding of the lecture contents, reading materials chosen from related textbooks or research articles were also provided. The course book, including handouts for the online lectures and reading materials, were distributed to students 1 week prior to the beginning of the course.

\section{2) Pre-tests}

The tutors motivated the students for independent study with persistent reminders to complete the preclass learning activities prior to class. For this purpose, we instructed the tutors to create pre-tests consisting of 10 multiple-choice questions from their designated sessions. We urged the tutors to create simple questions focused on the content covered in the pre-class materials, since the primary purpose of the test was to assist students' preparedness rather than to grade them. At the beginning of each session, the students took a 10-minute pre-test. Group discussion or questions were not allowed during this time.

\section{3) In-class materials}

We provided case studies for each session as in-class materials. Three cases were originally developed by the Center for Disease Control and Prevention, and one each by the Association of Teachers of Preventive Medicine and the Korean Society for Preventive Medicine. Each case began with a brief description of actual epidemiological events, followed by 10 to 20 step-by-step questions logically designed to explain how learners can approach certain concepts of epidemiology. The students were encouraged to manage the questions through active group discussion or online searches based on what they had learned from the pre-class materials. During this period, the tutors also actively rotated among the assigned groups to ascertain whether the students had any difficulties, answer their questions, and provide detailed explanations when necessary. At the end of each session, the students summarized the results of the case study based on the group discussions. They gave a short presentation of their work, and the tutors provided feedback. Finally, the students submitted a brief group report on the case study.

\section{4) Post-class assessment}

The group reports were evaluated by a tutor on the same day they were submitted. The focus of this evaluation was to check for student misunderstandings of key concepts and common errors. Supplementary comments along with a final summary of the key issues from each session were added to the reports and sent back to the students on the same day. The report feedback was managed by a single tutor throughout the course to ensure timely responses, consistency, and uniform explanations of the key concepts. At the beginning of each session, the students were provided with grade reports from the previous session's pre-test so as to keep them on track. The report was also given after the mid-term exam of the affiliated 'preventive medicine' course. The students who scored in the bottom percentile were given an alert advising them to pay more attention to the class materials. In addition, for the students who sought additional help or had difficulties with the independent study, the tutor provided a personalized counseling session at their request.

\section{Session preparation}

On the day of each session, the tutors held a preview 
conference led by the organizing professor. The tutors reviewed the results from the previous session, such as the pre-test scores or group reports, and discussed additional explanations to be provided to the students when necessary. They also previewed the course materials for each day and identified the key concepts to be delivered to ensure that sessions were facilitated in a uniform manner.

\section{Course overview}

The structure of the 'practice of epidemiology' course is summarized in Table 1. For the five sessions of the course, the pre-class materials consisted of online lectures and assigned readings, and we prepared the pretests according to the corresponding titles. The online lecture for the fourth session was divided into two parts for the sake of length, and no additional reading material was assigned. The viewing rates, indicating total views divided by the number of students, increased from $22.5 \%$ to $101 \%$ for the first three lectures. This indicates that some students viewed the lecture more than once.

\section{Statistical analysis}

We planned to evaluate students' performance change (i.e., quantitative evaluation) and adaptation to the new setting. For the former, we first analyzed the results of five pre-tests to measure the effects of the pre-class materials. Furthermore, we also assessed the relevance of the pre-class study and pre-test results through multiple regression analysis. We compared the results of the pre-tests and final exams to assess the effectiveness of the flipped learning method. For the latter, we conducted pre- and post-course surveys using a questionnaire composed of questions about various aspects of the flipped classroom design [10-12]. Descriptive statistics with standard deviations were computed. In addition, we compared the results of the study instruments, such as the pre- and post-course survey results, using paired t-tests. Finally, we conducted data management and statistical analyses using SAS ver. 9.4 (SAS Institute Inc., Cary, USA) and R-Studio ver. 1.0.153 (RStudio Inc., Boston, USA).

\section{Ethical considerations}

Since the medical students were defined as vulnerable study participants, we strictly observed the relevant requirements and regulations. The students were informed about the study's purpose and associated data collection along with the course outline. Those who agreed with the study purpose and data collection submitted a written consent form voluntarily. The overall study design, including student protection

\begin{tabular}{|c|c|c|c|c|c|}
\hline Session title & $\begin{array}{c}\text { 1. Descriptive } \\
\text { epidemiology: epidemic } \\
\text { disease in a community }\end{array}$ & $\begin{array}{l}\text { 2. Validity and reliability: } \\
\text { screening for human } \\
\text { immunodeficiency virus }\end{array}$ & $\begin{array}{l}\text { 3. Surveillance } \\
\text { system: injury } \\
\text { surveillance }\end{array}$ & $\begin{array}{c}\text { 4. Outbreak } \\
\text { investigation: students } \\
\text { have diarrheal }\end{array}$ & $\begin{array}{l}\text { 5. Study design: oral } \\
\text { contraceptives and } \\
\text { ovarian cancer }\end{array}$ \\
\hline Video length (min) & 21 & 32 & 24 & $\begin{array}{l}\text { One: } 15 \\
\text { Two: } 29\end{array}$ & 16 \\
\hline Views $(\%)$ & $27(22.5)$ & 95 (79.2) & $128(101)$ & $\begin{array}{l}\text { One } 106(88.3) \\
\text { Two: } 73(60.8)\end{array}$ & $85(70.8)$ \\
\hline Assigned reading(s) & 18 Pages & 21 Pages & 5 Pages & Not assigned & 27 Pages \\
\hline Pre-test questions & $\begin{array}{l}6 \mathrm{MCO}+2 \\
\text { short-answer }\end{array}$ & 10 MCQ & $8 \mathrm{MCO}$ & $10 \mathrm{MCO}$ & 10 MCQ \\
\hline
\end{tabular}

MCQ: Multiple-choice question.

${ }^{a}$ Two online lectures were prepared for the fourth session. 
measures, was reviewed and approved by the Korea University Institutional Review Board (approval no., 1040548-KU-IRB-17-205-A-1).

\section{Results}

We evaluated students' utilization and perception of the pre-class materials in four aspects: preparedness, relevance, difficulty, and length (Table 2). First, whether a student watched/read the online lectures or assigned readings before coming to class, and, if so, how many times, constituted Preparedness. While more than half of the students (63 [66\%]-75 [77\%]) answered that they had watched the online lecture for each session at least once, more than half of the students (53 [55\%]-65 [67\%]) were found to be unprepared for the assigned readings. Second, the purpose of the pre-tests was to check whether the students had studied the pre-class materials. Therefore, the concepts in the pre-class materials had to be relevant to those tested in the pre-tests, and so students were asked whether the online lectures or assigned readings were helpful in completing the pre-tests. Relevance was above average for both types of materials (online lecture 3.68 \pm 1.15 , assigned reading $3.46 \pm 0.71$ for session 1) at the beginning of the course but decreased over time, especially for the online lectures (online lecture 1.90 \pm 1.01 , assigned reading $2.90 \pm 1.06$ for session 5). Likewise, their perception of 'difficulty' was higher later in the course, and this increase was steeper with the online lectures. However, the 'length' of the online lectures seemed appropriate, except for the fourth session, which had two videos, in comparison with the assigned readings.

Students' opinions of their states of preparedness are suggested in Supplement 1. Those who were less

Table 2. Students' Utilization and Perception of Online Lectures and Assigned Readings

\begin{tabular}{|c|c|c|c|c|c|}
\hline Response items & Session 1 & Session 2 & Session 3 & Session 4 & Session 5 \\
\hline \multicolumn{6}{|l|}{ Online lectures } \\
\hline \multicolumn{6}{|l|}{ Watched before class } \\
\hline More than once & $4(4.2)$ & $4(4.1)$ & $5(5.3)$ & $3(3.1)$ & $5(5.2)$ \\
\hline Once & $63(65.6)$ & $68(70.1)$ & $71(74.7)$ & $70(72.9)$ & 75 (77.3) \\
\hline Partly & $18(18.8)$ & $10(10.3)$ & $7(7.4)$ & 14 (14.6) & 7 (7.2) \\
\hline Did not watch & 11 (11.5) & 15 (15.5) & 12 (12.6) & $9(9.4)$ & 10 (10.3) \\
\hline Relevance in pretest ${ }^{a}$ & $3.68 \pm 1.15$ & $3.04 \pm 1.01$ & $2.90 \pm 1.07$ & $2.72 \pm 1.02$ & $1.90 \pm 1.01$ \\
\hline Difficulty $^{\mathrm{bl}}$ & $2.60 \pm 0.89$ & $3.10 \pm 0.95$ & $3.30 \pm 0.92$ & $3.51 \pm 0.97$ & $3.70 \pm 1.14$ \\
\hline Length $^{c \mid}$ & $3.06 \pm 0.71$ & $3.22 \pm 0.72$ & $3.19 \pm 0.76$ & $4.40 \pm 0.85$ & $2.57 \pm 0.91$ \\
\hline \multicolumn{6}{|l|}{ Assigned readings } \\
\hline \multicolumn{6}{|l|}{ Read before class } \\
\hline More than once & $2(2.1)$ & $1(1.0)$ & $2(2.1)$ & $N A^{d l}$ & $2(2.1)$ \\
\hline Once & 21 (21.9) & $20(20.6)$ & $20(20.8)$ & & $18(18.6)$ \\
\hline Partly & $20(20.8)$ & $11(11.3)$ & $13(13.5)$ & & $13(13.4)$ \\
\hline Did not read & $53(55.2)$ & $65(67.0)$ & $61(63.5)$ & & $64(66.0)$ \\
\hline Relevance in pretest ${ }^{a l}$ & $3.46 \pm 0.71$ & $3.19 \pm 0.79$ & $3.09 \pm 0.75$ & NA & $2.90 \pm 1.06$ \\
\hline Difficulty ${ }^{\mathrm{b})}$ & $3.07 \pm 0.69$ & $3.48 \pm 0.77$ & $3.38 \pm 0.78$ & NA & $3.47 \pm 1.08$ \\
\hline Length $^{\mathrm{cl}}$ & $3.35 \pm 0.74$ & $3.43 \pm 0.68$ & $3.26 \pm 0.75$ & NA & $3.56 \pm 0.88$ \\
\hline
\end{tabular}

Data are presented as number $(\%)$ or mean \pm standard deviation.

NA: Not assessed.

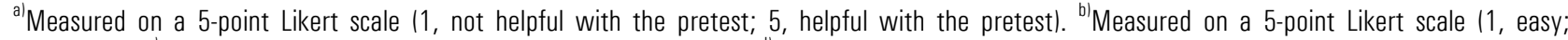
5, difficult). ${ }^{\text {cl }}$ Measured on a 5-point Likert scale (1, short; 5, long). ${ }^{\text {d) }}$ Session 4 did not have assigned reading material. 
prepared for either the online lectures or assigned readings overwhelmingly stated that they had not had enough time to study the materials in advance (40 [70\%] and 114 [49\%], respectively). Interestingly, 85 (36\%) unprepared students mentioned that they did not know they were supposed to study the assigned readings beforehand. Students who at least tried to study the pre-class materials but did not finish them also cited a lack of time as an excuse. The results showed that such difficulty was especially evident when studying the reading materials, with $89 \%$ (51) of the students having experienced the same problem. Meanwhile, 71\% (5) of the students who replayed the online video pointed out that it was challenging to understand all the lecture contents the first time.

We considered the four aspects of the utilization and perception of pre-class materials described in Table 2 as predictive factors of pre-class study achievements, using pre-test scores as the outcome measure. Among the factors, the consistency and difficulty of both the online lectures and assigned readings showed a significant correlation with learning outcomes (Table 3). Interestingly, although many students cited a lack of time as a barrier to effective independent study, lengthy online lectures were significantly predictive of better learning outcomes (Table 3).

\begin{tabular}{|c|c|c|c|c|c|c|}
\hline \multirow{3}{*}{ Factor } & \multicolumn{6}{|c|}{ Course material } \\
\hline & \multicolumn{3}{|c|}{ Online lectures } & \multicolumn{3}{|c|}{ Assigned readings } \\
\hline & Coefficient & SE & $p$-value & Coefficient & SE & $p$-value \\
\hline Preparedness ${ }^{\text {al }}$ & 1.364 & 2.738 & 0.618 & -0.947 & 3.54 & 0.79 \\
\hline Relevance ${ }^{b /}$ & 7.971 & 0.952 & $<0.001$ & 7.638 & 2.61 & 0.004 \\
\hline Difficulty ${ }^{c l}$ & -6.333 & 1.102 & $<0.001$ & -6.01 & 2.953 & 0.044 \\
\hline Length $^{\text {dl }}$ & 2.92 & 1.09 & 0.008 & 1.46 & 3.528 & 0.68 \\
\hline
\end{tabular}

SE: Standard error.

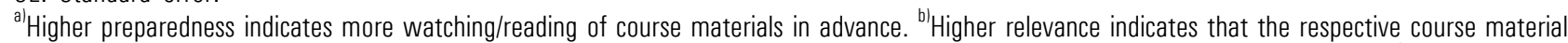
was helpful for the pre-test. Measured on a 5 -point Likert scale (1, not helpful with the pre-test; 5 , helpful with the pre-test). ${ }^{\text {c) }}$ Measured on a 5-point Likert scale (1, easy; 5, difficult). ${ }^{\text {d) }}$ Measured on a 5-point Likert scale (1, short; 5, long).

Table 4. Students' Attitudes and Perspectives on the Practice of Epidemiology Course before and after Completion

\begin{tabular}{|c|c|c|c|}
\hline Survey question ${ }^{\mathrm{a}}$ & Pre-course & Post-course & p-value \\
\hline \multicolumn{4}{|l|}{ Preparedness } \\
\hline I understand the purpose and study objective of the course. & $3.26 \pm 0.94$ & $3.57 \pm 0.99$ & 0.03 \\
\hline \multicolumn{4}{|l|}{ Participation } \\
\hline I actively participate(d) in in-class activities such as group discussions or presentations. & $3.38 \pm 1.15$ & $3.80 \pm 1.01$ & $<0.001$ \\
\hline $\begin{array}{l}\text { I try (tried) to make up for what I don't (didn't) understand clearly by asking for help } \\
\text { (ask instructor, ask/discuss with friends/refer to supplementary materials, etc.). }\end{array}$ & $2.78 \pm 1.05$ & $3.58 \pm 1.02$ & 0.08 \\
\hline \multicolumn{4}{|l|}{ Effectiveness (in understanding the course) } \\
\hline I have (had) no problem understanding the course. & $3.35 \pm 0.99$ & $2.90 \pm 1.07$ & 0.39 \\
\hline Group discussions or presentations are (were) helpful in understanding the course. & $2.99 \pm 0.97$ & $3.42 \pm 1.01$ & $<0.001$ \\
\hline I understand the key points of the course. & $2.97 \pm 0.95$ & $3.32 \pm 0.91$ & $<0.001$ \\
\hline I am confident about how to study for the course. & $2.99 \pm 0.90$ & $3.04 \pm 1.08$ & 0.21 \\
\hline \multicolumn{4}{|l|}{ Satisfaction } \\
\hline I had/gained interest in preventive medicine. & $2.85 \pm 0.95$ & $3.07 \pm 1.17$ & 0.82 \\
\hline I am generally satisfied with the course. & $3.03 \pm 0.97$ & $3.32 \pm 0.98$ & 0.93 \\
\hline
\end{tabular}

Data are presented as mean \pm standard deviation.

${ }^{\text {a) }}$ Measured on a 5-point Likert scale (1, strongly disagree; 5, strongly agree). 
The pre- and post-course survey of students' attitudes and perspectives on the 'practice of epidemiology' class are described in Table 4. Statistically meaningful changes were observed in the following categories: preparedness, participation, and effectiveness. However, students overall satisfaction with the course showed a merely insignificant change.

Fig. 1 illustrates the quantitative learning achievements measured by the pre-tests and final exam scores. As described, the pre-tests were conducted prior to every session. During the course of the semester, however, we recognized that the classroom environment, which was set up to facilitate small group discussion, was unsuited to administering individual exams. Since such a situation could bias the study's results, during the final two sessions we implemented a new pre-test format that was individualized for every student in each group while maintaining identical questions and discarded the results from the first three sessions. The overall results did not

Fig. 1. Comparison of Pre-test and Final Exam Results for the Different Subsets of Questions

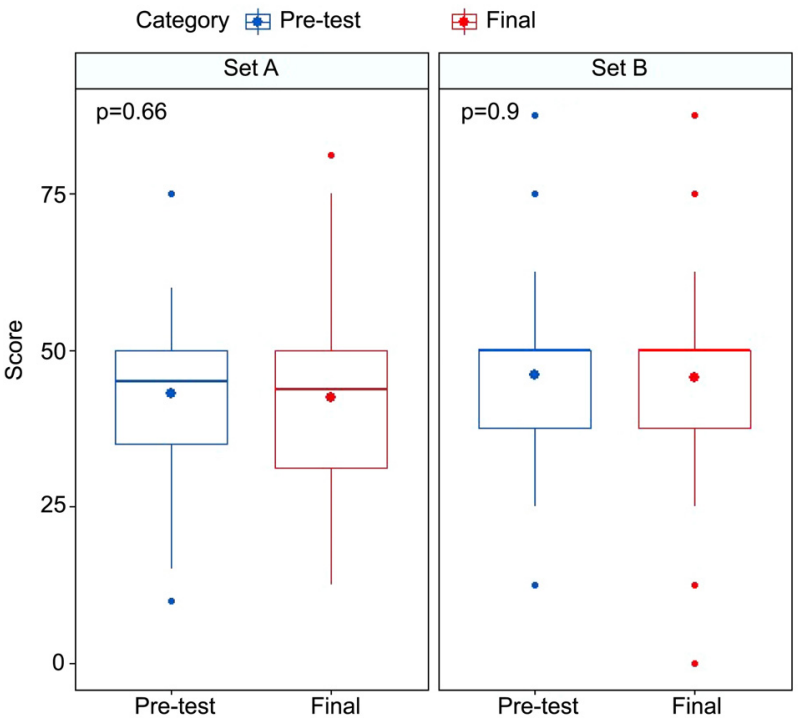

Set A: Scores on the fourth and fifth session pre-test questions and final exam questions corresponding to those sessions. Set B: Scores on the subsets of questions from the fourth and fifth pre-tests that were repeated on the final exam, and final exam questions that were identical to those questions. show significant differences between the pre-tests and final exam (average score difference $=-0.68, \mathrm{p}=0.66$ ). Narrowing the results to the subsets of questions on the pre-tests and the same questions again on the final exam did not yield a significant difference either (average score difference $=-0.26, \mathrm{p}=0.90$ ).

\section{Discussion}

The authors' new trial of flipping the class in the undergraduate epidemiology course showed promising results in terms of students' preparedness, class participation, and effectiveness in understanding the course. The students were able to understand the working logic of a flipped classroom after finishing the course and were prepared to meet the learning objectives of problem-solving competency against actual public health issues. They evaluated the effect of interactions with peers and tutors for better understating of the course highly. Their attitudes toward active participation in class discussions and presentations also improved significantly throughout the course, as in a previous study [5].

However, it was not apparent whether the students gained more interest in this subject or were satisfied after the course. After reviewing students' written comments on our course (Supplement 2), we assume that the students struggled to manage the pre-class materials on their own. Student comments on this topic included, "The course is overwhelming for only two credits," "I'm unsatisfied that the instructors are teaching us more than they are supposed to," and "The online lectures lacked explanations, while the pre-tests required advanced knowledge." These opinions are understandable because, despite our instructions to the tutors to keep the course material integrated and appropriate for the students' 
level of understanding, some tutors condensed too much information into the pre-class readings and lectures. This implies that we should have focused more on providing a better tutor training program for this new instruction method.

Meanwhile, our findings showed that the online lectures were instrumental in the students' learning. Our finding that a significant proportion of the students watched the online lectures prior to class was consistent with previous studies $[8,12,14,15]$. Based on the regression results, however, such a high rating does not seem to guarantee better learning outcomes, despite the findings of other reports [10]. One positive interpretation is that our course materials were ideally organized, so improved student achievement cannot be explained by a single factor [16]. A more likely explanation, however, is that merely providing materials to improve learning outcomes might demand too much from students [17]. We are now aware of different ways of making medical courses much more effective with the help of various out-of-class materials [16,18]. Fortunately, students are also very familiar with digital learning tools and are open to formats adopting such learning materials [8,14]. A positive aspect of technology is that numerous varied study materials can be easily retrieved and distributed. However, this leads to serious misperceptions, both on the part of students that they will fully understand the content by just clicking on it, and on the part of instructors that students will study all the materials distributed to them $[17,19]$.

The students' indifference toward and low utilization of the reading materials can be understood likewise. Even in studies showing the positive effects of online lectures, the role of reading materials was inconclusive $[11,20]$. Successful self-directed learning can be achieved when students are ready to accept new information or at least manage their learning goals [21]. Meanwhile, the third-year medical students who participated in the present study were learning medical terms and concepts for the first time in their lives and therefore had no background in the subject [9]. This factor is critical in subjects such as epidemiology that require some understanding of both basic and clinical medicine. Under these circumstances, meeting the tutors' high expectations might have been overwhelming for many students [19].

In short, significant attention should be paid to producing more organized and relevant pre-class materials based on established instructional rules and principles [22,23]. Instructors should first focus on the learning contents that students can handle rather than on what the instructors themselves desire to deliver. When seeking this instructional balance, the students' perceptions of the consistency and difficulty of pre-class materials may provide clues concerning the likely learning outcomes.

We compared the summary of pre-test and final exam scores to evaluate the quantitative effectiveness of the flipped learning approach. To minimize irrelevant effects from a small-group study room where the students could discuss their answers with others, we prepared individualized test sheets in last two sessions. We also repeated several questions from the pretests on the final exam to evaluate the learning outcome. Nevertheless, neither a significant improvement nor a decline in student scores was observed at the end of the course, in line with studies in similar settings [24]. Limited studies indicating improved quantitative outcomes for flipped over traditional classes had different settings from ours, as they involved graduate students who already had sufficient backgrounds in medical knowledge [20], or gave the pre-test and post-test right before and after the session, respectively, so that memory effects would not affect the study's results [9]. To confirm the quantitative effectiveness of the flipped 
learning model in medical education, further studies are needed in different settings such as repeated tests right after the session and the entire course, as well as randomized comparisons between the flipped and traditional methods using identical course materials and evaluation tools.

To the best of our knowledge, few existing studies have described the specific composition of tutors. We successfully organized the flipped class with four qualified instructors who also participated as tutors, and two graduate school students who helped run the sessions. Medical school staffs in Korea, as well as other countries with under-resourced educational environments, have heavy workloads that involve patient care, research, and student education at the same time. Moreover, since medical education has such a small window for trial and error because of its special purposes, there are not many opportunities for the implementation of new teaching formats. Under these circumstances, institutions willing to implement the flipped learning model should also take the available workforce into consideration as a significant aspect of the requirements.

We would like to share the lessons from this study with educators who are considering a flipped classroom model in limited or similar educational contexts as ours. The provision of redundant lectures is one issue that might have affected our study. Although there are no stated rules, it is recommended that the flipped classroom entirely flip the class and thus involve no in-class lectures [4]. In our study, however, the practice of epidemiology' course was scheduled in parallel with the 'preventive medicine' course. Since the key concepts had already been taught through this 'preventive medicine' lecture, this might have discouraged students' engagement in the pre-class, self-directed learning activities. In a similar context, our attention to the flawless structural design of the new method might have relatively weakened our attention to in-class activities. Although there are no ground rules on what should be done in class or how much the tutors can intervene [4], we could have given them more flexibility by blending pre-class works during in-class or modulating the tutors' role from passively answering questions to actively encouraging students [11].

Some limitations on our study should be considered. Since our main purpose was the implementation of a new system, we adopted survey items and domains from previous studies [10-12] instead of developing a new study tool. While there are suggestions that different systems require different evaluating methods [4], we regard the results of conventional tools as also holding merit for general understanding or assumptions of tendencies. Another limitation was that it was not until the end of the course that we could recognize which device students preferred when studying online lectures. As most students were using portable devices with relatively small screens (Supplement 3), increasing the font size and ensuring sufficient contrast would have facilitated online lecture viewing. In a similar vein, we could not accurately measure how long the students could concentrate, nor could we check the precise viewing rates [13]. However, many higher education institutions now provide professional lecture management systems (LMS) such as 'Blackboard.' With the help of a professional LMS, these issues may be resolved easily.

In conclusion, our study supports the feasibility of the flipped classroom model even under a traditional, heavily scheduled undergraduate medical curriculum, especially in terms of students' preparedness and engagement in the course. To encourage self-directed learning and achieve better learning outcomes, however, we also suggest considering restructuring other pre- 
existing curricular components in parallel with implementing a novel instructional method.

\section{Supplementary materials}

Supplementary files are available from https://doi.org/ 10.3946/kjme.2019.122.

Supplement 1. Reasons for Incomplete Preparedness or Repeated Study of Course Materials.

Supplement 2. Students' Post-course Feedback on the Flipped Learning Design.

Supplement 3. Students' Post-course Feedback on Course Components of the Flipped Class Design.

\section{ORCID:}

Sangho Sohn: https://orcid.org/0000-0003-2736-3461; Young-Mee Lee: https://orcid.org/0000-0002-4685-9465; Jaehun Jung: https://orcid.org/0000-0002-4856-3668;

Eun Shil Cha: https://orcid.org/0000-0001-5059-5776; Byung Chul Chun: https://orcid.org/0000-0001-6576-8916

Acknowledgements: The authors would like to express their gratitude to the 2017 first-year medical students of Korea University College of Medicine for their active participation in this study. The authors would also like to thank Korea University Graduate School of Public Health students Wonju Cho and Jin A Kim for their support in running the class and facilitating the administrative work. Finally, the authors would like to express their deep appreciation to Medical Education Center research assistant Hyelim Kim and Academic Affairs Department staff member Yongjin Lee, who assisted the study with their expert management of the students and course evaluations, and who willingly shared their expertise and evaluation tools.

Funding: Not applicable.

Conflicts of interest: No potential conflict of interest relevant to this article was reported.

Author contributions: Conception and design of the study: SS, YML, BCC; acquisition, analysis, and interpretation of the data: SS, BCC; acquisition of study data: JJ, ESC; critical revision: YML, JJ, ESC; drafting the article: SS; and final approval of the version to be published and agreement of its publication: SS, YML, JJ, ESC, BCC.

\section{References}

1. Schwartzstein RM. Getting the right medical students: nature versus nurture. N Engl J Med. 2015;372(17): 1586-1587.

2. Crisp N, Chen L. Global supply of health professionals. N Engl J Med. 2014;370(23):2247-2248.

3. Vernon DT, Blake RL. Does problem-based learning work?: a meta-analysis of evaluative research. Acad Med. 1993;68(7):550-563.

4. Bergmann J, Sams A. Flip your classroom: reach every student in every class every day. Eugene, USA: International Society for Technology in Education; 2012.

5. Chun KH, Lee YH. Improvement of debate competence: an outcome of an introductory course for medical humanities. Korean J Med Educ. 2016;28(1):87-93.

6. Prober CG, Heath C. Lecture halls without lectures: a proposal for medical education. N Engl J Med. 2012; 366(18):1657-1659.

7. Evans KH, Thompson AC, O'Brien C, et al. An innovative blended preclinical curriculum in clinical epidemiology and biostatistics: impact on student satisfaction and performance. Acad Med. 2016;91(5):696-700.

8. Park JH, Park KH, Lee YI. Development of cyber lecture contents and application to the basic neuroscience integrative lecture for medical students. J Korea Acad Ind Coop Soc. 2011;12(5):2222-2229. 
9. Veeramani R, Madhugiri VS, Chand P. Perception of MBBS students to "flipped class room" approach in neuroanatomy module. Anat Cell Biol. 2015;48(2):138143.

10. Ihm J, Choi H, Roh S. Flipped-learning course design and evaluation through student self-assessment in a predental science class. Korean J Med Educ. 2017;29(2): 93-100.

11. McLaughlin JE, Roth MT, Glatt DM, et al. The flipped classroom: a course redesign to foster learning and engagement in a health professions school. Acad Med. 2014;89(2):236-243.

12. Pierce R, Fox J. Vodcasts and active-learning exercises in a "flipped classroom" model of a renal pharmacotherapy module. Am J Pharm Educ. 2012;76(10):196.

13. Stuart J, Rutherford RJ. Medical student concentration during lectures. Lancet. 1978;2(8088):514-516.

14. Tang B, Coret A, Qureshi A, Barron H, Ayala AP, Law M. Online lectures in undergraduate medical education: scoping review. JMIR Med Educ. 2018;4(1):el1.

15. O'Flaherty J, Phillips C. The use of flipped classrooms in higher education: a scoping review. Internet High Educ. 2015;25:85-95.

16. Lee YM. Connect medical education practices and research in Asia with the rest of world. Korean J Med Educ. 2017;29(1):3-5.

17. Schwartzstein RM, Roberts DH. Saying goodbye to lectures in medical school: paradigm shift or passing fad? N Engl J Med. 2017;377(7):605-607.

18. Irby DM, Cooke M, O'Brien BC. Calls for reform of medical education by the Carnegie Foundation for the Advancement of Teaching: 1910 and 2010. Acad Med. 2010;85(2):220-227.

19. Schmidt HG. Assumptions underlying self-directed learning may be false. Med Educ. 2000;34(4):243-245.

20. Tune JD, Sturek M, Basile DP. Flipped classroom model improves graduate student performance in cardiovascular, respiratory, and renal physiology. Adv Physiol Educ. 2013;37(4):316-320.

21. Hendry GD, Ginns P. Readiness for self-directed learning: validation of a new scale with medical students. Med Teach. 2009;31(10):918-920.

22. Issa N, Mayer RE, Schuller M, Wang E, Shapiro MB, DaRosa DA. Teaching for understanding in medical classrooms using multimedia design principles. Med Educ. 2013;47(4):388-396.

23. Association of American Medical Colleges. Effective use of educational technology in medical education. https:// members.aamc.org/eweb/upload/Effective\%20Use\%20of \%20Educational.pdf. Published March 2007. Accessed August 31, 2018.

24. Shiau S, Kahn LG, Platt J, et al. Evaluation of a flipped classroom approach to learning introductory epidemiology. BMC Med Educ. 2018;18(1):63. 